\title{
Genome-Wide Identification of Plant-Upregulated Genes of Erwinia chrysanthemi 3937 Using a GFP-Based IVET Leaf Array
}

\author{
Shihui Yang, ${ }^{1}$ Nicole T. Perna, ${ }^{2}$ Donald A. Cooksey, ${ }^{1}$ Yasushi Okinaka, ${ }^{3}$ Steven E. Lindow, ${ }^{4}$ A. Mark \\ Ibekwe, ${ }^{5}$ Noel T. Keen, ${ }^{1}$ and Ching-Hong Yang ${ }^{6}$ \\ ${ }^{1}$ Department of Plant Pathology, University of California, Riverside 92521, U.S.A.; ${ }^{2}$ Department of Animal Health and \\ Biomedical Sciences, University of Wisconsin-Madison 53706, U.S.A.; ${ }^{3}$ Graduate School of Biosphere Science, Hiroshima \\ University, Kagamiyama 1-4-4, Higashi-hiroshima, 739-8528, Japan; ${ }^{4}$ Department of Plant and Microbial Biology, University \\ of California, Berkeley 94720, U.S.A.; ${ }^{5}$ United States Department of Agriculture-Agricultural Research Service George E. \\ Brown Jr. Salinity Lab., Riverside, CA 92507, U.S.A., ${ }^{6}$ Department of Biological Sciences, University of Wisconsin- \\ Milwaukee 53211, U.S.A.
}

Submitted 22 December 2003. Accepted 3 May 2004.

A green fluorescent protein-based in vivo expression technology leaf array was used to identify genes in Erwinia chrysanthemi 3937 that were specifically upregulated in plants compared with growth in a laboratory culture medium. Of 10,000 E. chrysanthemi 3937 clones, 61 were confirmed as plant upregulated. On the basis of sequence similarity, these were recognized with probable functions in metabolism $(20 \%)$, information transfer $(15 \%)$, regulation $(11 \%)$, transport $(11 \%)$, cell processes $(11 \%)$, and transposases $(2 \%)$; the function for the remainder $(\mathbf{3 0} \%)$ is unknown. Upregulated genes included transcriptional regulators, iron uptake systems, chemotaxis components, transporters, stress response genes, and several already known or new putative virulence factors. Ten independent mutants were constructed by insertions in these plant-upregulated genes and flanking genes. Two different virulence assays, local leaf maceration and systemic invasion in African violet, were used to evaluate these mutants. Among these, mutants of a purM homolog from Escherichia coli (purM::Tn5), and hrpB, hrcJ, and a hrpD homologs from the Erwinia carotovorum hrpA operon (hrpB::Tn5, hrcJ::Tn5, and hrpD::Tn5) exhibited reduced abilities to produce local and systemic maceration of the plant host. Mutants of rhiT from E. chrysanthemi (rhiT:: Tn5), and an eutR homolog from Salmonella typhimurium (eutR::Tn5) showed decreased ability to cause systemic inva sion on African violet. However, compared with the wildtype $E$. chrysanthemi 3937, these mutants exhibited no significant differences in local leaf maceration. The pheno type of $h r p B:: \operatorname{Tn} 5, h r c C:: \operatorname{Tn} 5$, and $h r p D:: T n 5$ mutants further confirmed our previous findings that hrp genes are crucial virulence determinants in $E$. chrysanthemi 3937.

Additional keywords: oxidative stress, phosphotransferase system, transport of oligogalacturonides, type III secretion system.

Erwinia chrysanthemi is an opportunistic necrotrophic pathogen that causes soft rot, wilts, and blight diseases on a wide range of plant species. Like other many enteric patho-

Corresponding author: Ching-Hong Yang; Telephone: +1-414-229-6331; Fax: +1-414-229-3926; E-mail: chyang@uwm.edu

N. T. Keen passed away on April 18, 2002. gens, such as Escherichia coli O157:H7 and Yersinia pestis, Erwinia chrysanthemi cells do not appear to invade host cells internally in the pathogenic phase. They remain in the intercellular spaces of infected plant tissue and use several secretion systems to inject virulence factors into host cells. In addition to causing local disease, the bacteria may enter vascular elements of infected plants, thereby moving rapidly through the host (Chatterjee et al. 2000; Collmer and Keen 1986; Expert 1999; Hugouvieux-Cotte-Pattat et al. 1996; Perombelon and Kelman 1980).

Many virulence determinants have been discovered in $E$. chrysanthemi, including the well-studied extracellular enzymes such as pectate lyase, pectinase, and cellulase; siderophore-dependent iron uptake systems, sap, and $m s r A$ gene (Expert 1999; Franza and Expert 1991; Franza et al. 1999; Hassouni et al. 1999; Lopez-Solanilla et al. 2001; Tardy et al. 1997). Virulence gene expression in E. chrysanthemi is a highly regulated phenomenon affected by a variety of parameters, including temperature, $\mathrm{pH}$, iron levels, growth phase, and population density. This organism uses complex regulation strategies for virulence gene expression and possesses wellknown sophisticated sensing systems such as ExpI/ExpR quorum sensing and two-component signal transduction pathways to sense and respond to environmental signals. It also utilizes transcriptional regulators such as cyclic AMP receptor protein (CRP), plant-inducible regulator (Pir), KdgR and PecS, and the RsmA/rsmB post-transcriptional regulatory system to coordinate virulence gene expression (Chatterjee et al. 2000; Franza et al. 1999; Hugouvieux-Cotte-Pattat et al. 1996; Nachin and Barras 2000; Nassar and Reverchon 2002; Nasser et al. 1994, 1998). Recently, the type III secretion system also has been reported to play a role in pathogenicity (Bauer et al. 1994, 1995; Lopez-Solanilla et al. 2001; Yang et al. 2002).

Virulence genes of pathogens can be divided into class I, class II, and class III categories according to Wassenaar and Gaastra (2001). Class I genes are called "true virulence genes", class II genes include global or specific regulators that regulate the activities of the class I genes, and class III virulence genes compromise host defense, cytoskeletal structure, and intracellular signaling, or encode other devices required for the pathogen to cope effectively with the nutrition-limited and generally hostile environment found within hosts. The distinction between class III virulence genes and housekeeping 
genes may be blurred. One major distinction is that, unlike true housekeeping genes, class III virulence genes are expected to be upregulated in the host environment compared with growth of the pathogen on laboratory culture media.

Unlike other host-specific plant bacterial pathogens, E. chrysanthemi is an opportunistic plant pathogen and attacks many different species of hosts. It is especially important to identify class III virulence genes in this unique bacterium because class III genes may facilitate E. chrysanthemi infection and colonization in a wide variety of plant hosts (Okinaka et al. 2002; Yang et al. 2002). Our results with microarray and mutagenesis experiments to study host upregulated genes of $E$. chrysanthemi 3937 on African violet have revealed several new class III virulence genes in the bacterium (Okinaka et al. 2002). Bacterial genes involved in virulence are likely to be plant inducible; therefore, instead of simply looking at type III secretion genes by sequence analysis and hrp functional assays (Boch et al. 2002; Fouts et al. 2002; Okinaka et al. 2002), we intend to identify diverse classes of virulence gene by using green fluorescent protein (GFP)-based in vivo expression technology (IVET) leaf array.

Beyond identification of virulence genes in E. chrysanthemi 3937, a broader understanding of host-regulated genes in this bacterium during the infection process is needed. Until now, various plant-regulated virulence genes of $E$. chrysanthemi 3937 have been identified (Expert 1999; Franza and Expert 1991; Franza et al. 1999; Hassouni et al. 1999; LopezSolanilla et al. 2001; Tardy et al. 1997), but little information is available on general host upregulated genes of the bacterium at a genomic level. In many infected plant tissues, a common shift in metabolic pattern, including activation of peroxidase and accumulation of an array of secondary metabolic substances (phenolics, flavonoids, coumarins, steroids, and so on) was observed (Goodman et al. 1986). As a consequence, many bacterial genes involved in growth inside of the plants might not necessarily be virulence genes, and altered global gene expression patterns are expected as the bacteria tailor their gene expression to adapt themselves inside of host plants (Okinaka et al. 2002). To broaden our understanding in this area, a stable GFP-based IVET leaf assay technique was introduced in this study to identify genes in E. chrysanthemi 3937 that are upregulated in a spinach host plant. Combining with the genome analysis database ASAP (a systematic genome package for community analysis of genomes) (Glasner et al. 2003), 10,000 individual IVET clones of E. chrysanthemi 3937 were screened for host upregulated genes and the identified genes were assigned to seven categories on the basis of their predicted cellular or physiological functions. Several plant upregulated genes were further selected and their roles in virulence on a plant host were investigated by two different assays, local leaf maceration and systemic invasion, on African violet. Several mutants of E. chrysanthemi 3937 caused local maceration but had reduced ability to cause systemic infection of the plant host.

\section{RESULTS}

\section{IVET screening plant-upregulated genes.}

The validity of our promoter-probe screening was tested with promoters of known virulence genes $h r p G, h r p N$, and pelD. Using a promoter-probe vector, pPROBE-AT (Miller and Lindow 1997), as a transcriptional reporter, a weak GFP fluorescence was observed from wild-type $E$. chrysanthemi 3937 cells containing promoter $h r p N$ (pPROBE-AT::PhrpN) and pelD (pPROBE-AT::PpelD) grown in Luria-Bertani (LB) broth (Table 1). No to very weak expression of GFP was observed from E. chrysanthemi 3937 cells containing plasmid
pPROBE-AT::PhrpG grown in LB broth. All three promoters of $h r p G, h r p N$, and pelD were found to be upregulated and produced elevated green fluorescent light in spinach leaves. No GFP expression was observed in wild-type E. chrysanthemi 3937 cells that contained the pPROBE-AT vector alone, or constructs pPROBE-AT::PhrpGop, pPROBE-AT::PhrpNop, and pPROBE-AT::PpelDop, in which the promoter sequences were in the opposite orientation with respect to the promoterless GFP promoter. Further verification of the IVET screening system was done by constructing a microarray clone ECH205 (Bacillus subtilis peptide synthase homolog, plant/culture ratio 5.4) (Okinaka et al. 2002) promoter region into pPROBE-AT vector as described above, and upregulated expression of GFP was observed in spinach leaves.

Plant upregulated clones of E. chrysanthemi were visually distinguished by a fluorescent microscope. To insure the consistency of our IVET screening, only the E. chrysanthemi library clones leading to bacterial fluorescence of similar or higher intensity as pPROBE-AT:PhrpG, and pPROBE-AT::PhrpN in leaves and no or low fluorescence in LB broth, were recognized as plant upregulated clones. The library clones showed minor differences in fluorescence signal within LB broth and plant leaf discs were eliminated because of the limitation of this method.

A library of 1.5-kb fragments of genomic DNA of wild-type E. chrysanthemi 3937 was ligated into the promoter-probe vector, pPROBE-AT. From 10,000 clones screened in spinach leaves, 61 plant-up-regulated clones of E. chrysanthemi 3937 were identified (Table 2). These upregulated clones were divided into seven functional categories, including metabolism $(20 \%)$, information transfer $(15 \%)$, regulation (11\%), transport $(11 \%)$, cell processes $(11 \%)$, and transposases $(2 \%)$. The function of the remaining $30 \%$ is unknown.

Among these plant-upregulated genes, several known or new putative virulence factor homologues of Erwinia spp. and other pathogens were identified. These include the type III secretion genes $h r p A$ and $h r p B$, which also have been found in Pseudomonas syringae by the IVET method (Boch et al. 2002). The $d s p E$ homologue, observed for the first time in $E$. chrysanthemi 3937, is an essential pathogenicity factor that is secreted through the type III secretion pathway in E. amylovora (Bogdanove et al. 1998; Gaudriault et al. 1997). A potential hrp box, the consensus binding site sequence of the alternative sigma factor $h r p L$, was found upstream of the $h r p A\left(5^{\prime}-\right.$ GGAACCACCTCGCATTATCTCCTACTTA-3') and $d s p E$ genes (5'-GGAACCGGCGGCGGCGGCATACCACTCA-3') of E. chrysanthemi 3937 . In addition, genes involved in cell wall degradation and sugar transport also were identified as upregulated in spinach. These included type II secretory component (out genes), oligogalacturonate lyase ( ogl), and a rhamnogalacturonide transporter $(r h i T)$. Peptide methionine sulfoxide reductase $(m s r A)$, which repairs oxidized proteins and protects $E$. chrysanthemi cells from oxidative stress in host environments (Hassouni et al. 1999), also was found to be upregulated in our assay. In addition, we found that the indigoidine gene (indA), conferring resistance to oxidative stress (Reverchon et al. 2002), also was upregulated in the plant hosts.

Several regulatory genes were found to be upregulated in the host plant from our IVET assay. These include the LysRfamily transcriptional regulatory protein MetR, the AraC-family regulatory proteins EutR and XylR, the IclR-family transcriptional regulator SrpS, the phosphate regulon transcriptional regulatory protein $\mathrm{PhoB}$, the transcription factor RelB, and the cyclic AMP receptor protein CRP. CRP is a main activator of pectinolysis genes in E. chrysanthemi 3937 (Reverchon et al. 1997). Although we failed to recover iron uptake genes previously reported in E. chrysanthemi 3937 (Expert 1999; 
Franza et al. 1999), several new putative iron uptake genes (yfeA, hmuS/hmuT/hmuU) were identified from our IVET assay. Several putative xenobiotic resistance genes (bacA and $\operatorname{crc} B$ ), chemotaxis signaling related genes (cheR and $\operatorname{trg}$ ), and a phosphotransferase system (PTS) gene (nagE) were found to be plant upregulated. In addition, we discovered several putative exported proteins with unknown function that were plant upregulated in the IVET assay. Five genes (ASAP IDs 14870, $16412,18371,19359$, and 19592) were chosen as the representative of transporter, metabolism, regulator, and type III secretion pathway, respectively, for the future study.

\section{Plant-upregulated gene knockout and virulence assays.}

Using the in vitro Tn5 insertional mutagenesis strategy, we constructed mutations in five plant upregulated genes and five adjacent open reading frames (ORFs) that might contribute to virulence. ASAP IDs 16412, 14870, 18371, 19592, and 19359 were plant upregulated genes identified in IVET assay. ASAP IDs 18369 and 18373 were genes flanking 18371.
ASAP IDs 19590, 19588, and 19586 were genes flanking 19592. Mutants of E. chrysanthemi 3937 were considered to have reduced local leaf maceration ability when their pathogenicity index (PI) values were <1. Mutants hrpB::Tn5, hrcJ::Tn5, and hrpD::Tn5 of E. chrysanthemi 3937, with PI values of $0.019,0$, and 0.016 , respectively, exhibited lower local leaf maceration in African violet (Fig. 1; Table 3). In addition, they showed reduced ability to cause systemic invasion in African violet (Fig. 2). Although the ability to produce local maceration was not significantly altered for the rhiT::Tn5 and eutR::Tn5 mutants of E. chrysanthemi 3937, systemic invasiveness was impaired in both. Seven days after inoculation, 8 of 10 plants inoculated with wild-type $E$. chrysanthemi 3937 developed systemic invasion, while 3 and 4 of 10 plants developed similar symptoms in the eutR::Tn5 and rhiT::Tn 5 mutants, respectively. Only 1 of 10 African violet plants developed systemic maceration symptoms in the hrpB::Tn5 mutant. Using the statistical Fisher's exact test, there was a significant difference in systemic maceration capac-

Table 1. Strains, plasmids and DNA primers used in this study

\begin{tabular}{|c|c|c|}
\hline Strains, plasmids, primers & Characters or sequences $\left(5^{\prime} \text { to } 3^{\prime}\right)^{a}$ & Reference or source \\
\hline \multicolumn{3}{|l|}{ Erwinia chrysanthemi strains } \\
\hline 3937 & Wild type & Hugouvieux-Cotte-Pattat, N. \\
\hline 3937 ирр::Tn5 & Tn5 Insertional mutant of $u p p$ homolog, $\mathrm{Km}^{\mathrm{r}}$ & This work \\
\hline 3937 rhiT::Tn5 & $\mathrm{Tn} 5$ Insertional mutant of $r h i T, \mathrm{Km}^{\mathrm{r}}$ & This work \\
\hline 3937 uraA::Tn5 & Tn5 Insertional mutant of $u r a A$ homolog, $\mathrm{Km}^{\mathrm{r}}$ & This work \\
\hline 3937 eutR::Tn5 & Tn5 Insertional mutant of eutR homolog, $\mathrm{Km}^{\mathrm{r}}$ & This work \\
\hline 3937 purM::Tn5 & Tn5 Insertional mutant of purM homolog, $\mathrm{Km}^{\mathrm{r}}$ & This work \\
\hline 3937 hrpB::Tn5 & Tn5 Insertional mutant of $h r p B$ homolog, $\mathrm{Km}^{\mathrm{r}}$ & This work \\
\hline 3937 hrcJ::Tn5 & Tn5 Insertional mutant of $h r c J$ homolog, $\mathrm{Km}^{\mathrm{r}}$ & This work \\
\hline 3937 hrpD::Tn5 & Tn5 Insertional mutant of $h r p D$ homolog, $\mathrm{Km}^{\mathrm{r}}$ & This work \\
\hline 3937 pup $2 D:: \operatorname{Tn} 5$ & Tn5 Insertional mutant of ECH19586, $\mathrm{Km}^{\mathrm{r}}$ & This work \\
\hline 3937 ECH16413::Tn5 & Tn5 Insertional mutant of ECH16413, $\mathrm{Km}^{\mathrm{r}}$ & This work \\
\hline \multicolumn{3}{|l|}{ Plasmids } \\
\hline pPROBE-AT & Promoter-probe vector, $\mathrm{Ap}^{\mathrm{r}}$ & Miller and Lindow 1997 \\
\hline pGEMT-Easy & PCR cloning vector, $\mathrm{Ap}^{\mathrm{r}}$ & Promega \\
\hline pPROBE-AT: PhrpG & 0.65 -kb DNA fragment in pBROBE-AT containing $h r p G$ promoter & This work \\
\hline pPROBE-AT::PhrpN & 0.5 -kb DNA fragment in pBROBE-AT containing $h r p N$ promoter & This work \\
\hline pPROBE-AT::PpelD & 0.6-kb DNA fragment in pBROBE-AT containing pelD promoter & This work \\
\hline pPROBE-AT::PhrpGop & The transcription orientation of $h r p G$ promoter is opposite to GFP reporter & This work \\
\hline pPROBE-AT::PhrpNop & The transcription orientation of $h r p N$ promoter is opposite to GFP reporter & This work \\
\hline pPROBE-AT::PpelDop & The transcription orientation of pelD promoter is opposite to GFP reporter & This work \\
\hline \multicolumn{3}{|c|}{ W } \\
\hline pPBROBE-AT For & ACTGCCAGGAATTGGGGATCGGAAG & $\ldots$ \\
\hline pPBROBE-AT Rev & AGTTCTTCTCCTTTACTCATA & $\ldots$ \\
\hline hrpG Forward & GTCGACGGATAACCCGCAAAAACCGG & $\ldots$ \\
\hline hrpG Reverse & TCAGTTGAAGTCATTGATGATGGCCTTC & $\ldots$ \\
\hline hrpN Forward & TCGCTCGTCGTTATCAGCAG & $\ldots$ \\
\hline hrpN Reverse & TCAGTTTATCCACGCTGGAACC & $\ldots$ \\
\hline pelD Forward & CGGTAAACTGTAATTTCCCGCCCAGCG & $\cdots$ \\
\hline pelD Reverse & TCATCGATGTAGCGATGATGGCTGCC & $\ldots$ \\
\hline Tn5 IR-F & GGTTGAGATGTGTATAAGAGACAG & $\ldots$ \\
\hline Tn5 IR-R & CCAACTCTACACATATTCTCTGTC & $\ldots$ \\
\hline CH205 Forward & AAGCTTGTCAGTCAGGCAGGACAA & $\ldots$ \\
\hline CH205 Reverse & GGATCCTGGAGTCTGGGTGAAGT & $\cdots$ \\
\hline PUP2 Forward & ACCTTACGCCACACGATCGG & $\ldots$ \\
\hline PUP2 Reverse & CGGAACCACCTCGCATTATC & $\ldots$ \\
\hline PUP5 Forward & CTTGAGCTCGATCGCCA & $\ldots$ \\
\hline PUP5 Reverse & TCAGCACGAATACCACGT & $\begin{array}{l}\cdots \\
\cdots\end{array}$ \\
\hline PUP5 Mutation Forward & GATGGCGTCCAACCTGAT & $\ldots$ \\
\hline PUP5 Mutation Reverse & AGAGAAGAACGTGGCGAT & $\ldots$ \\
\hline PUP16 Forward & TCATGACGGCTGACGTTG & $\ldots$ \\
\hline PUP16 Reverse & TGGCTTCGTAGGTCAGCA & $\ldots$ \\
\hline PUP16 Mutation Forward & CGATGTCAGTACCAAGCG & $\begin{array}{l}\cdots \\
\cdots\end{array}$ \\
\hline PUP16 Mutation Reverse & GGCAACGTCAGCCGTCAT & $\ldots$ \\
\hline PUP21 Forward & CATGGGCCGCGTAGTCGATA & $\ldots$ \\
\hline PUP21 Reverse & CGCCCTGGTGAAACAACAGA & $\cdots$ \\
\hline PUP29/30 Forward & GGTCAGGAACATGGTCAC & $\cdots$ \\
\hline PUP29/30 Reverse & GACACCTGACTGACAGGT & $\cdots$ \\
\hline PUP29/30 Mutation Forward & TATCTTGTGCCCTTTGGC & $\ldots$ \\
\hline PUP29/30 Mutation Reverse & GGGCGTAATGTTTCTGGT & $\ldots$ \\
\hline
\end{tabular}

\footnotetext{
${ }^{\mathrm{a}} \mathrm{Km}^{\mathrm{r}}=$ kanamycin resistance and $\mathrm{Ap}^{\mathrm{r}}=$ ampicillin resistance.
} 
ity between the wild-type bacterium and the eutR::Tn5 $(P=$ 0.032), hrpB::Tn5 $(P=0.02)$, and rhiT::Tn5 $(P=0.075) \mathrm{mu}-$ tants. The purM::Tn5 mutant is an auxotroph and was not able to grow on M9 minimum medium. No significant reduction of virulence was observed in the other Tn5 mutants constructed.

\section{DISCUSSION}

Recently, microarray gene expression technology was used to identify gene expression profiles of organisms in different environments (DeLisa et al. 2001; Okinaka et al. 2002; Wei et al. 2001). However, several limitations (e.g., low amount of available RNA from target cells and the presence of contaminating organisms in samples) still deter the usage of this modern technology (Marco et al. 2003). A variety of IVET strategies, including the differential fluorescence induction (DFI) of GFP in cells, host-specific complementation of nutritional auxotrophies, and expression of selectable antibiotic resistance genes, remained the most comprehensive approaches to identify bacterial genes induced in a host- or habit-specific environment (Heithoff et al. 1997; Mahan et al. 1993, 1995; Rainey 1999; Valdivia and Falkow 1996, 1997; Wang et al. 1996). Recently, a novel IVET screening strategy termed habitat-inducible rescue of survival (HIRS) was further developed to identify genes of $P$. syringae that were weakly expressed on plants (Marco et al. 2003). Several limiting factors (e.g., the choice of baseline for genes to be considered 'off' in vitro) also have been reported that influenced the type and number of genes identified from this promoter trap strategy. In addition, the level of induction in vivo also was affected by the location, extent, and duration of these environment-inducible genes in IVET assays (Boch et al. 2002; Marco et al. 2003).

E. chrysanthemi 3937 is an opportunistic necrotrophic bacterial pathogen that attacks a wide range of plant species (Chatterjee et al. 2000; Collmer and Keen 1986; HugouvieuxCotte-Pattat et al. 1996; Perombelon and Kelman 1980). Until now, limited information was available on gene expression profiles of $E$. chrysanthemi 3937 during host-microbe interactions (Aguilar et al. 2002; Okinaka et al. 2002). To discover plant upregulated genes of E. chrysanthemi 3937 in a genomewide level, we combined the genome analysis database ASAP with a GFP-based IVET leaf array to do a mass screening of bacterial genes that are specifically upregulated in spinach. Compared with the plant-upregulated genes of E. chrysanthemi identified from the previous microarray analysis (Okinaka et al. 2002), only a few identical genes (e.g., yfe and $h m u U$ ) were identified in our IVET assay. However, many different genes with similar functions were identified in microarray and IVET studies. The major plant-upregulated genes with similar functions identified in both assays include chemotaxis genes; genes homologous to PTS; genes related to xenobiotic resistance; putative oxidoreductases; genes involved in transposi-

Table 2. Plant-upregulated genes of Erwinia chrysanthemi 3937 identified from a green fluorescent protein-based in vivo expression technology leaf array assay using spinach as a host plant

\begin{tabular}{|c|c|c|c|}
\hline Clone ID & ASAP feature ID & Homologous gene (organism) & Product, functions \\
\hline PUP-1 & 19012 & dspE (Erwinia amylovora) & Type III secretion system effector \\
\hline \multirow{2}{*}{ PUP-2 } & 19593 & $\operatorname{hrp} A($ E. carotovora $)$ & Type III protein secretion system pilus subunit \\
\hline & 19592 & hrpB $($ E. carotovora $)$ & HrpB, type III protein secretion system \\
\hline PUP-3 & 18752 & cheR (Yersenia pestis) & Chemotaxis protein methyltransferase \\
\hline PUP-4 & 18585 & $\operatorname{trg}($ Escherichia coli) & Methyl-accepting chemotaxis protein III, ribose sensor receptor \\
\hline PUP-5 & 14870 & rhiT (E. chrysanthemi) & Rhamnogalacturonide transporter \\
\hline \multirow[t]{2}{*}{ PUP-6 } & 20728 & out $F($ E. carotovora $)$ & Type II secretory pathway component \\
\hline & 20727 & out $G($ E. carotovora $)$ & Type II secretory pathway component \\
\hline PUP-7 & 20503 & $n a g E(Y$. pestis $)$ & PTS system, N-acetylglucosamine-specific IIABC \\
\hline PUP-8 & 15122 & yfeA (Y.pestis) & Iron (chelated) $\mathrm{ABC}$ transporter, periplasmic protein \\
\hline \multirow[t]{3}{*}{ PUP-9 } & 19507 & hmuS (Y.pestis) & Hemin degrading protein $\mathrm{HmuS}$ \\
\hline & 19508 & hmuT (Y.pestis) & $\mathrm{ABC}$ transporter, periplasmic hemin-binding protein \\
\hline & 19509 & hтиU (Y. pestis) & Hemin $A B C$ transporter, permease \\
\hline PUP-10 & 16084 & indA $($ E. chrysanthemi $)$ & Indigoidine biosynthesis protein IndA \\
\hline PUP-11 & 17182 & ppK (Escherichia coli K12) & Polyphosphate kinase \\
\hline PUP-12 & 14816 & msrA $($ E. chrysanthemi $)$ & Peptide methionine sulfoxide reductase \\
\hline PUP-13 & 16562 & iaaM (Pseudomonas agglomerans) & Tryptophan 2-monooxygenase \\
\hline PUP-14 & 16562 & iaaM (P. agglomerans) & Tryptophan 2-monooxygenase \\
\hline PUP-15 & 17720 & ppc (Escherichia coli) & Phosphoenolpyruvate carboxylase \\
\hline PUP-16 & 18371 & upp (Escherichia coli K12) & Uracil phosphoribosyltransferase \\
\hline PUP-17 & 17543 & phoB (Escherichia coli) & Two-component system Pi regulon response regulator \\
\hline PUP-18 & 19992 & relB (Vibrio cholerae) & RelB protein \\
\hline PUP-19 & 17715 & metR $(Y \cdot$ pestis $)$ & LysR-family transcriptional regulator \\
\hline PUP-20 & 15482 & $\operatorname{crp}($ E. chrysanthemi $)$ & CRP regulator \\
\hline PUP-21 & 19359 & eutR (Salmonella typhimurium) & Ethanolamine operon regulator \\
\hline PUP-22 & 16098 & xylR (Escherichia coli K12) & Xylose operon regulator, AraC-family \\
\hline PUP-23 & 20033 & $\operatorname{srpS}(P . p u t i d a)$ & Transcriptional regulator, Crp family \\
\hline PUP-24 & 18849 & atu0245 (Agrobacterium tumefaciens) & Transcriptional regulator, Cro/CI family \\
\hline PUP-25 & 20364 & yhjH $($ S. typhimurium $)$ & Diguanylate cyclase/phosphodiesterase domain 3 \\
\hline PUP-26 & 16993 & pheA (P. agglomerans) & Chorismate mutase-P/prephenate dehydratase \\
\hline PUP-27 & 17052 & rimJ (Escherichia coli K12) & Acetyltransferase \\
\hline PUP-28 & 18478 & PA4512 (P. aeruginosa) & Dioxygenase \\
\hline PUP-29 & 16414 & y2956 (Y. pestis) & Virulence protein \\
\hline PUP-30 & 16412 & yicJ (Escherichia coli) & Sodium galactoside symporter \\
\hline PUP-31 & 15477 & YPOO181 (Y.pestis) & $\mathrm{ABC}$ transport protein \\
\hline PUP-32 & 19554 & STY0495 (S. enterica) & Exported protein \\
\hline
\end{tabular}


tion, recombination, or DNA repair; putative iron acquisition genes; and other transporters. Using the microarray assay, RNA expression profiles were determined at the instant of sampling time. On the other hand, using a GFP-based reporter, an accumulation of the upregulated signals from bacterial inoculation until harvest was recognized. Different host plants were used in our microarray and IVET assays. These might explain why, in many cases, different plant-upregulated bacterial genes with similar functions were identified in microarray and IVET assays.

With the advantage of the stability of the long-life GFP, host-upregulated genes of E. chrysanthemi 3937 during the 18-h infection period in spinach were recognized and divided into different functional categories. Our study indicated that $70 \%$ of these plant-upregulated genes in E chrysanthemi 3937 could be assigned to functional categories. During disease development, a similar ratio of genes involved in regulation $(11 \%)$, transport $(11 \%)$, and cell process $(11 \%)$ were upregulated in E. chrysanthemi 3937. It is possible that the induction of transposase genes (2\%) in the plant host may have occurred from the stress in the plant environment (Ilves et al. 2001; Okinaka et al. 2002).

Several genes were identified with probable roles in stress response to reactive oxygen species. These included peptide methionine sulfoxide reductase $(m s r A)$ and the indA. IVET work done in Streptococcus gordonii also identified the msrA gene induced in endocarditis of the New Zealand white rabbit (Kilic et al. 1999). MsrA can repair oxidatively damaged proteins and is required for full virulence of $E$. chrysanthemi (Hassoouni et al. 1999). IndA is involved in biosynthesis of the blue pigment indigoidine and protects the bacteria against the reactive oxygen species generated during the plant defense response (Reverchon et al. 2002). This might indicate that active oxygen species were produced from the host plant to defend against the invading pathogen and the pathogens make use of different products to protect themselves from the oxidative stresses.

Six transcriptional factors (PhoB, MetR, CRP, EutR, XylR, and SrpS) and one unknown regulator (ASAP ID 18849) were found to be upregulated in spinach in this study. PhoB is a component of a two-component signal transduction pathway. MetR, CRP, EutR, XylR, SrpS, and the unknown regulator contained a helix-turn-helix (HTH) motif either at the N-terminus (MetR, SrpS, and unknown regulator) or at the C-terminus (CRP, EutR, and XylR). PUP-25 contained an EAL domain (pfam00563), which is a good candidate for a diguanylate phosphodiesterase function. In E. chrysanthemi, several transcriptional factors related to pathogenicity have been investigated intensely by other researchers. These include the positive regulators CRP, Pir, and ExpR, and negative regulators, such as KdgR, PecS, and PecT (Chatterjee et al. 2000; Franza et al. 1999; Hugouvieux-CottePattat et al. 1996; Nassar and Reverchon 2002; Nasser et al. 1994, 1998). The recruitment of many regulators may indicate that successful pathogenicity requires complex gene regulation and expression for rapid adaptation to the complicated and di-

Table 2. (Continued from previous page)

\begin{tabular}{|c|c|c|c|}
\hline Clone ID & ASAP feature ID & Homologous gene (organism) & Product, functions \\
\hline PUP-33 & 15731 & YPO0661 (Y.pestis) & Exported protein \\
\hline PUP-34 & 19297 & b1329 (Escherichia coli K12) & $\mathrm{ABC}$ transporter, periplasmic murein peptide-binding \\
\hline PUP-35 & 19750 & $\operatorname{glpM}(Y$. pestis $)$ & Membrane protein \\
\hline PUP-36 & 19662 & YPO2922 (Y.pestis) & Membrane protein \\
\hline PUP-37 & 20770 & RSO2521 (Ralstonia solanacearum) & Membrane protein \\
\hline PUP-38 & 19164 & yhhA $($ S. typhimurium $)$ & Outer membrane protein \\
\hline PUP-39 & 15150 & yaaA (S. typhimurium) & Cytoplasmic protein \\
\hline PUP-40 & 16622 & STM4501 (S. typhimurium) & Cytoplasmic protein \\
\hline PUP-41 & 16622 & STM4501 (S. typhimurium) & Cytoplasmic protein \\
\hline PUP-42 & 20093 & Cj0014c (Campylobacter jejuni) & Integral membrane protein \\
\hline PUP-43 & 15890 & XCC4050 (Xanthomonas campestris) & Ankyrin-related protein \\
\hline PUP-44 & 17185 & STY0862 (S. enterica $)$ & Zinc-finger containing protein \\
\hline PUP-45 & 17186 & ynaF $(S$. typhimurium $)$ & Universal stress protein \\
\hline PUP-46 & 17186 & ynaF $($ S. typhimurium $)$ & Universal stress protein \\
\hline PUP-47 & 18343 & $\operatorname{crcB}($ Escherichia coli K12) & Chromosome condensation protein \\
\hline PUP-48 & 18876 & XAC3843 (Xanthomonas axonopodis) & Unknown protein \\
\hline PUP-49 & 16049 & Unknown protein & Unknown protein \\
\hline PUP-50 & 20543 & yqgA (Shigella flexneri) & Unknown protein \\
\hline PUP-51 & 20034 & STY2446 $(S$. enterica $)$ & Unknown protein \\
\hline PUP-52 & 17269 & $\operatorname{vgrG}(Y \cdot$ pestis $)$ & VgrG-like protein \\
\hline PUP-53 & 17269 & $\operatorname{vgrG}(Y$. pestis $)$ & VgrG-like protein \\
\hline \multirow[t]{2}{*}{ PUP-54 } & 20121 & tnpA $($ E. chrysanthemi $)$ & Transposase \\
\hline & 20118 & ogl (E.chrysanthemi) & Oligogalacturonate lysase \\
\hline \multirow[t]{2}{*}{ PUP-55 } & 20619 & ansA $(Y$. pestis $)$ & Cytoplasmic L-asparaginase I \\
\hline & 19584 & pncA (Y.pestis) & Pyrazinamidase/nicotinamidase \\
\hline \multirow[t]{2}{*}{ PUP-56 } & 14828 & bacA (Y.pestis) & Undecaprenol kinase, bacitracin resistance protein \\
\hline & 14827 & folB (Y. pestis) & Dihydroneopterin aldolase \\
\hline \multirow[t]{2}{*}{ PUP-57 } & 17163 & ydfP (Bacillus subtilis) & Unknown protein \\
\hline & 17162 & $\operatorname{cys} S(Y$. pestis $)$ & Cysteinyl-tRNA synthetase \\
\hline \multirow[t]{2}{*}{ PUP-58 } & 17061 & yecM $($ S. typhimurium $)$ & Unknown protein \\
\hline & 17062 & cutC $(Y$. pestis $)$ & Copper homeostasis protein \\
\hline \multirow[t]{3}{*}{ PUP-59 } & 16275 & pstB (Escherichia coli) & High-affinity Pi ABC transporter, ATP binding protein \\
\hline & 16274 & phoU (Escherichia coli) & Phosphate transport system regulator \\
\hline & 16270 & YPO4111 (Y.pestis) & Periplasmic solute-binding protein \\
\hline \multirow[t]{2}{*}{ PUP-60 } & 20706 & phnC $(Y$. pestis $)$ & Pi uptake $\mathrm{ABC}$ transporter, ATP-binding protein \\
\hline & 20707 & phnD $(Y$. pestis $)$ & Pi uptake $\mathrm{ABC}$ transporter, periplasmic protein \\
\hline PUP-61 & 18644 & XCC2096 (X. campestris) & Unknown protein \\
\hline
\end{tabular}


verse plant host environment (Buell et al. 2003). Unraveling the secrets of the temporal and spatial expression pattern in E. chrysanthemi 3937 regulators may help us understand its adaptation and fitness in host environments.

Iron is in short supply in numerous environments, and many bacteria secrete siderophores specifically to chelate iron. In our studies, various putative iron-uptake genes, including hmuSTU and $y f e A$ homologues, were recognized as plant upregulated. Similarly, many genes related to iron metabolism were found to be induced with the IVET approach in other bacterial pathogens. These include entF and fhuA in S. typhimurium, fur and fptA in P. aeruginosa, and fepA in Klebsiella pneumoniae (Heithoff et al. 1997; Lai et al. 2001; Wang et al. 1996). In E. chrysanthemi, two structurally unrelated siderophores, chrysobactin and achromobactin, were identified. Chrysobactin is required for the bacterium to cause systemic infection in African violet. Plant hosts inoculated with an $E$. chrysanthemi achromobactin mutant exhibit delayed symptoms (Expert 1999; Franza et al. 1999).

Two redundant transport systems, TogMNAB and TogT, have been identified in E. chrysanthemi 3937 and are able to independently mediate the transport of oligogalacturonides through the inner membrane of this bacterium. Inactivation of both systems is necessary to give a clear phenotype of transportation deficiency (Hugouvieux-Cotte-Pattat and Reverchon 2001; Hugouvieux-Cotte-Pattat et al. 2001). There is strong evidence that the newly identified rhiT plays a role in the uptake of rhamnogalacturonides (Hugouvieux-Cotte-Pattat 2004). Rhamnogalacturonides are generated by the extracellular enzyme RhiE, a $62-\mathrm{kDa}$ protein that has rhamnogalacturonate lyase activity on rhamnogalacturonan I (RG-I). The reduced virulence of the rhiE mutant indicates that degradation of the RG-I region of pectin is important for full virulence of E. chrysanthemi (Laatu and Condemine 2003). In this study, a disruption of rhiT in E. chrysanthemi 3937 did not significantly alter local maceration, but systemic invasion capability was compromised. The mechanism of reduced systemic invasion ability of the rhiT mutant in the host plant is unclear. One possibility is that a deletion of the rhiT gene in E. chrysanthemi 3937 could disrupt the production of other exoenzymes and pathogenicity factors regulated by degraded pectin and pectate intermediates (Toth et al. 2003). The precise production of these virulence factors during the infection process might be required for a systemic invasion of E. chrysanthemi 3937 in host plants. In any event, the rhiT mutant further reveals the importance of pectin utilization for E. chrysanthemi pathogenicity. Similarly, eutR::Tn5 mutants of E. chrysanthemi 3937 had a reduced capacity to invade systemically. Gathering more information from further local and systemic infection assays may perhaps help us explain the mechanism of delayed systemic infection.

Several plant-upregulated genes of E. chrysanthemi 3937 related to phosphate metabolism, transportation, and regulation were identified through the IVET assay. They include $p p K$,

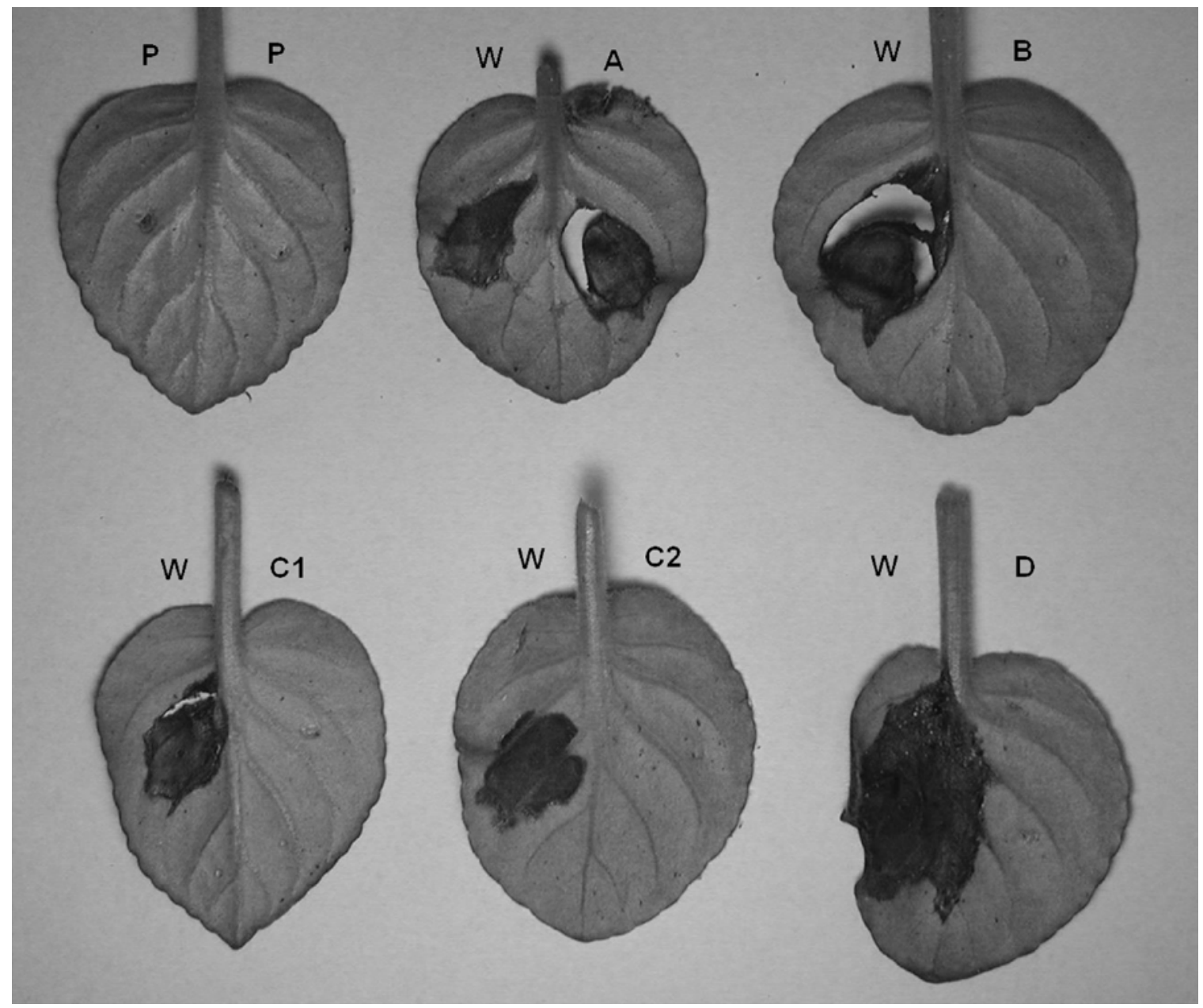

Fig. 1. Local maceration lesions caused by wild-type Erwinia chrysanthemi 3937 (W) and mutants pup2D::Tn5 (A), hrpD::Tn5 (B), hrcJ::Tn5 (C1 and C2), and hrpB::Tn5 (D) on leaves of African violet cv. Katja. Bacterial cells were inoculated in the middle of each half side of the same leaf. Phosphate buffer (pH 7.4, 50 $\mathrm{mM}$ ) were used to suspend the bacterial cells and a volume of $0.05 \mathrm{ml}$ of bacterial suspension with a bacterial concentration of $10^{6} \mathrm{CFU} / \mathrm{ml}$ was used. P indicates leaves infiltrated with phosphate buffer alone. Both $\mathrm{C} 1$ and $\mathrm{C} 2$ are $h r c J$ mutants with $\mathrm{Tn} 5$ transposon insertion at different locations of $h r c J$ gene. 
phoB, pstB, phnC, phnD, and a potential Pi ABC transporter periplasmic substrate-binding component homologue. Inorganic polyphosphate (Poly P) is a chain of many hundreds of phosphates (Pi) linked by high-energy phosphoanhydride bonds and widespread in all life forms. PPK is a bifunctional polyphosphate kinase that synthesizes polyphosphates from ATP or converts poly P and ADP to ATP. There are several potential functions for cellular Poly $\mathrm{P}$, including a phosphate and energy reservoir, a chelator of metal ions, a buffer against alkali, and a channel for DNA entry (Kim et al. 2002; Kornberg et al. 1999; Shiba et al. 2000). Some evidence has been gathered for the role of $p p K$ in virulence. For example, inorganic polyphosphate was required for motility of bacterial pathogens, and $p p K$ of $P$. aeruginosa is responsible for biofilm development, quorum sensing, and virulence (Rashid and Kornberg 2000; Rashid et al 2000a and b). Von Kruger and associates (1999) verified that a Vibrio cholerae phoB mutant was less able to colonize rabbit intestines than the wild-type bacterium. It will be interesting to further investigate whether or not the ppK and $p h o B$ of E. chrysanthemi 3937 are important for bacterial response to $\mathrm{Pi}$ starvation, virulence gene expression, and survival.
The bacterial PTS catalyzes sugar phosphorylation and dephosphorylation, and regulates a variety of bacterial physiological processes. It plays important roles in chemotaxis, intermediary metabolism, gene transcription, and virulence (Saier and Reizer 1994). In our IVET assay, a $n a g E$ homologue in $E$. chrysanthemi 3937 was upregulated in the plant host. NagE is a component of an $\mathrm{N}$-acetylglucosamine-specific IIABC PTS system, containing a PTS-EIIC conserved domain at the N-terminus and a PTS-EIIB conserved domain at the $\mathrm{C}$-terminus.

Bacteria use chemotaxis to respond to microenvironments by swimming toward or away from stimulants to optimize their growth and survival. Although a lot of work has been carried out on the role of motility as virulence factor for bacteria (Gosink et al. 2002; Larsen and Boesen 2001; O'Toole et al. 1996), little has been done on E. chrysanthemi. This study identified the cheR and $\operatorname{trg}$ homologues in E. chrysanthemi 3937 as upregulated in the plant host. An additional investigation about the interactions among chemotaxis, PTS, and Pi systems identified in the IVET assay may lead to an understanding of the regulatory mechanisms involved in the bacterial infection process. In addition, the upregulation of $n a g E$ (N-acetylglucosamine-specific PTS system component), b1329

Table 3. Local lesion maceration by wild-type Erwinia chrysanthemi 3937 and mutants on African violet cv. Katja

\begin{tabular}{|c|c|c|c|}
\hline Mutant $^{\mathrm{a}}$ & Potential function of mutated gene & ASAP ID $^{\mathbf{b}}$ & $\mathbf{P I}^{\mathbf{c}}$ \\
\hline ECH16412::Tn5 & Putative sodium galactoside symporter & 16412 & $0.708 \pm 0.135$ \\
\hline$r h i T:: \operatorname{Tn} 5$ & Rhamnogalacturonide transporter & 14870 & $1.821 \pm 0.830$ \\
\hline uraA::Tn5 & Uracil transporter & 18369 & $1.063 \pm 0.344$ \\
\hline upp::Tn5 & Uracil phosphoribosyl transferase & 18371 & $0.807 \pm 0.165$ \\
\hline purM::Tn5 & Phosphoribosylaminoimidazole synthetase & 18373 & $0.047 \pm 0.061$ \\
\hline$h r p B:: \operatorname{Tn} 5$ & Unknown, possible secretion & 19592 & $0.019 \pm 0.032$ \\
\hline$h r c J:: \operatorname{Tn} 5$ & Lipoprotein family protein & 19590 & 0 \\
\hline hrpD::Tn5 & Unknown, possible secretion & 19588 & $0.016 \pm 0.014$ \\
\hline pup $2 D:: \operatorname{Tn} 5$ & Putative Membrane-bound lytic murein transglycosylase & 19586 & $1.235 \pm 0.222$ \\
\hline eutR::Tn5 & Putative ethanolamine operon regulatory protein & 19359 & $0.794 \pm 0.093$ \\
\hline
\end{tabular}

${ }^{\text {a }}$ Except for the purM mutant, all mutant strains grew as well as the wild-type on M9 glucose minimal medium.

${ }^{\mathrm{b}}$ Identification numbers: 16412, 14870, 18371, 19592, and 19359 are plant-upregulated genes found in IVET screening; 18369 and 18373 are genes flanking $18371 ; 19590,19588$, and 19586 are genes flanking 19592.

${ }^{\mathrm{c}}$ Pathogenicity index $(\mathrm{PI})=\Sigma$ (lesion size of leaves from the bacterial mutant/lesion size of leaves from the wild-type bacterium)/number of leaves used for measurement. PI $<1$, the bacterial mutants had reduced virulence compared with the wild-type bacterium; PI $=1$, the bacterial mutants were as virulence as the wild-type bacterium; PI > 1, the bacterial mutants had enhanced virulence compared with the wild-type bacterium. Maceration area was calculated with American Phytopathological Society Assess software (St. Paul, MN, U.S.A.). Three replicate plants with a total of 12 leaves were inoculated for each of the wild-type bacterium and its mutants.

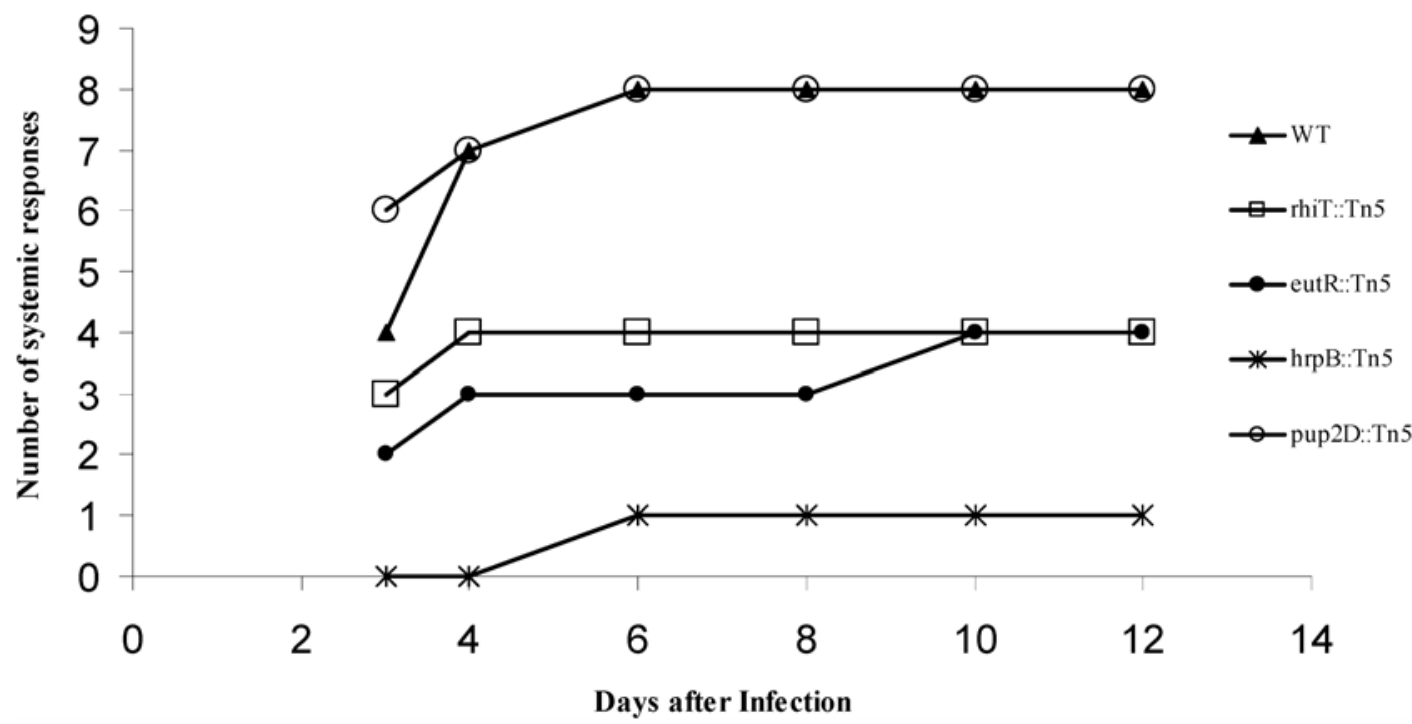

Fig. 2. Development of symptoms induced by Erwinia chrysanthemi 3937 wild type and rhiT::Tn5, eutR::Tn5, hrpB::Tn5, and pup2D::Tn5 mutant strains on African violet cv. Katja plants. A systemic invasion assay was used as described by Nachin and associates (2001) with minor modification. For each strain, 10 plants (one leaf per plant) were inoculated. Response was considered as systemic when at least one leaf and its petiole were macerated. 
(ABC transporter, periplasmic murein peptide-binding protein), and $b a c A$ (undecaprenol kinase, bacitracin resistance protein) all may be related to the increased need for cell wall growth during bacteria proliferate within the plant environment.

Various genes related to purine and pyrimidine biosynthesis have been reported in IVET and signature-tagged mutagenesis (STM) work. These include purCELK in Streptococcus spp.; purDHK, purKLFC, and carBA in V. cholerae; and purHLD in $P$. aeruginosa. The interruption of these genes may reduce the virulence of these pathogens in their hosts (Chiang and Mekalanos 1998; Lehoux et al. 2002; Merrell et al. 2002; Polissi et al. 1998). Although the purM homolog mutant (purM::Tn5) of E. chrysanthemi 3937 showed reduced virulence on African violet, it was unable to grow on M9 minimum medium. The cause of reduction in virulence of this mutant may be due to its auxotrophic phenotype. Other genes found in this IVET study were the genes involved in xenobiotic resistance, as well as several transposase genes that also were reported by other groups using IVET or STM approaches (Boch et al. 2002; Coulter et al. 1998; Kilic et al. 1999; Merrell et al. 2002; Wang et al. 1996; Wu et al. 2002).

Although the type III secretion system has been identified in E. chrysanthemi, relatively little is known about its role in pathogenicity (Bauer et al. 1994, 1995; Lopez-Solanilla et al. 2001; Yang et al. 2002). The mutants of $h r p B, h r c J$, and $h r p D$ homologues from the hrpA operon of E. chrysanthemi 3937 had reduced local leaf maceration and reduced systemic invasion abilities, which further confirmed our previous result that hrp genes in E. chrysanthemi 3937 are crucial for full virulence (Yang et al. 2002).

The rhiT and eutR genes of E. chrysanthemi 3937 identified in this study can be classified as class III virulence genes. However, a significant proportion of bacterial genes upregulated in plant hosts in this study are not necessarily for its pathogenicity. E. chrysanthemi is a bacterial pathogen that can infect a wide range of plant species. In this study, we identified a broad spectrum of genes in E. chrysanthemi 3937 that were upregulated in spinach. With the completion of E. chrysanthemi 3937 genome sequencing, it will be interesting to further compare arrays of genes in the bacterium that are regulated in different plant hosts and study how the bacterium coordinates gene expression to adapt to different host environments.

\section{MATERIALS AND METHODS}

\section{Bacterial strains, plasmids, and media.}

The bacterial strains and plasmids used in this study are listed in Table 1. Wild-type E. chrysanthemi 3937 and mutant strains were stored at $-80^{\circ} \mathrm{C}$ in $15 \%$ glycerol and grown on LB agar. Antibiotics used were kanamycin at $50 \mu \mathrm{g} / \mathrm{ml}$ and ampicillin at $100 \mu \mathrm{g} / \mathrm{ml}$. Primers used for polymerase chain reaction (PCR) in this report also are listed in Table 1.

\section{pPROBE-AT:PpelD, pPROBE-AT:PhrpG, and pPROBE- AT:PhrpN promoter vector construction.}

DNA fragments of pelD, hrpG, and $h r p N$ promoter regions were PCR amplified from E. chrysanthemi 3937 chromosomal DNA. The amplified DNA fragments were gel purified with QIAquick gel extraction kit (Qiagen, Valencia, CA, U.S.A.) and ligated into the pGEM-T Easy vector system containing 3'T overhangs at the insertion side (Promega Corp., Madison, WI, U.S.A.). The plasmid DNA was digested with EcoRI to release the pelD, $h r p G$, and $h r p N$ promoter fragments which were ligated into the promoter-probe vector pPORBE-AT at the EcoRI site. The orientation of the inserted DNA fragments in pPROBE-AT was determined by PCR. Plasmids containing DNA inserts with the correct (promoter transcribes toward
GFP promoter-probe cassettes) and the opposite orientations were selected. These plasmids were designated as pPROBEAT::PpelD, pPROBE-AT::PhrpG, pPROBE-AT::PhrpN (promoter with the transcription orientation toward the promoterless GFP reporter of pPROBE-AT), pPROBE-AT::PpelDop, pPROBE-AT::PhrpGop, and pPROBE-AT::PhrpNop (promoter with the transcription orientation opposite to promoterless GFP reporter). Seven different plasmids, pPROBE-AT:: P pelD, pPROBE-AT::PhrpG, pPROBE-AT::PhrpN, pPROBEAT::PpelDop, pPROBE-AT::PhrpGop, pPROBE-AT::PhrpNop, and the pPROBE-AT vector alone, were electroporated individually into wild-type E. chrysanthemi 3937 . Plasmid-containing bacteria were inoculated into spinach leaves and LB media. The GFP protein expression from bacteria was observed using an Olympus fluorescent microscope.

\section{GFP-based IVET leaf array screening strategy.}

A library of $1.5-\mathrm{kb}$ fragments of Sau $3 A 1$ partially digested genomic DNA of wild-type E. chrysanthemi 3937 was cloned by ligation into the BamHI site of the promoter-probe vector, pPROBE-AT. The $1.5-\mathrm{kb}$ chromosomal fragments were size fractionated through agarose gel eletrophoresis and further purified through QIAquick gel extraction kit. The pPROBE-AT plasmid contained a broad host-range replicon from $\mathrm{pBBR} 1$ and a promoterless GFP reporter. Random library clones constructed in pPROBE-AT were electroporated into wild-type E. chrysanthemi 3937 as described (Yang et al. 2002). The plasmid-containing bacteria were grown on LB agar at $28^{\circ} \mathrm{C}$ overnight and transferred into microtiter plates containing $3-\mathrm{mm}$ discs cut from market-purchased spinach leaves. Microtiter plates containing plant leaves and bacteria were vacuum infiltrated in a closed chamber to introduce bacteria into the leaf discs (with a vacuum pressure of $500 \mathrm{mmHg}$ for $3 \mathrm{~min}$, repeated six times). All leaf discs were incubated at $28^{\circ} \mathrm{C}$ for $18 \mathrm{~h}$ with moderate shaking. As controls, we used bacteria carrying the pPROBEAT vector alone and plasmids pPROBE-AT::PpelD, pPROBEAT::PhrpG, and pPROBE-AT::PhrpN that contained known $E$. chrysanthemi plant-inducible promoters of $h r p G$, pelD, and $h r p N$. After incubation, the leaf discs were mechanically macerated to release bacterial cells. The cell suspension was spotted on glass plates by using a hand arrayer and observed under a fluorescent microscope to monitor relative GFP fluorescence. Fluorescent bacteria were selected and rescreened on LB liquid medium and in spinach leaf discs. Bacterial clones leading to fluorescence of similar intensity between host leaves and LB broth were assumed to contain constitutive promoters and were discarded. Bacteria carrying plant upregulated promoters (no or lower fluorescence on LB medium compared with host leaf) were confirmed by rescreening on leaves and LB media. The consistent clones were end sequenced to identify the cloned genes or promoter regions.

\section{Sequencing and annotating candidate clones.}

Initially, sequencing primers were designed for primer walking to complete the full length of the insert DNA fragments in pPROBE-AT if end sequencing did not give the full length of the insert DNA fragments. The vector sequences were trimmed and remaining DNA sequences were assembled in Vector NTI (InforMax Inc., Bethesda, MD, U.S.A.). The ORF prediction and homologue search of ORFs were analyzed by Vector NTI through NCBI Blast searches. After the preliminary $E$. chrysanthemi 3937 genome sequence became available, the candidate clones were end sequenced from both ends and compared in ASAP to obtain the full-length sequence of insert DNA. The functional groups of plant-upregulated genes from our IVET assay were categorized accordingly (Glasner et al. 2003; Serres and Riley 2001). Several other bioinformatics 
tools were used to analyze their conserved motifs and putative functions, such as NIH NCBI Conserved Domain Database and Search Service (CDD), Kyoto Encyclopedia of Genes and Genomes (KEGG), and Escherichia coli genome and proteome databases (GenProtEC).

\section{Exploring the potential functions of plant-upregulated genes by Tn 5 mutagenesis and virulence assays.}

Initially, a pooled library screening strategy was used to identify Erwinia chrysanthemi 3937 library clones containing target genes for mutation. Specific PCR primers were designed for a 7- to 8-kb DNA insert library pool (48 library clones were pooled as one screening unit) of E. chrysanthemi 3937. Once an expected PCR DNA fragment was observed in $E$. chrysanthemi library pools, 48 insert library clones were amplified individually to obtain the library clone containing a target gene. Selected ORFs on plant-upregulated plasmid clones were mutagenized with Tn5 transposon using an EZ::TN $<\mathrm{KAN}-2>$ insertion kit with the procedures suggested by the manufacturer (Epicentre Technologies, Madison, WI, U.S.A.). Tn5 insertions were physically mapped and precisely located by sequencing with transposon primers IR-F or IR-R. The plasmid constructs then were electroporated into E. chrysanthemi 3937 and plasmid curing and marker exchange were accomplished by growth of kanamycin-resistant transformants in low-phosphate medium broth (Ried and Collmer 1987; Yang et al. 2002). Mutations in the resultant kanamycin-resistant and ampicillin-sensitive colonies then were confirmed by PCR, using transposon and target gene-specific primers.

Subsequently, PCR primers were designed for plantupregulated clones or genes based on the available E. chrysanthemi 3937 genome data. DNA fragments were amplified using a proofreading DNA polymerase (FailSafe PCR system; Epicentre), cloned into pGEM-Teasy vector, and mutated with Tn5, after which marker exchange mutagenesis was performed as described above.

Two different virulence assays, local leaf maceration and systemic invasion, were conducted on African violet cv. Katja leaves. In the local maceration assay, a volume of $0.05 \mathrm{ml}$ with a bacterial concentration of $10^{6} \mathrm{CFU} / \mathrm{ml}$ of wild-type $E$. chrysanthemi 3937 and its mutants was inoculated in the middle of each half side of the same leaf. Phosphate buffer ( $\mathrm{pH} 7.4,50$ $\mathrm{mM}$ ) was used to suspend the bacterial cells. The inoculated plants were placed in a growth chamber under the conditions described previously (Yang et al. 2002). Three replicate plants with a total of 12 leaves were inoculated for each of the wildtype bacterium and its mutants. The maceration area of plant leaves caused by the bacterial strains was precisely measured with an image analysis software, ASSESS (The American Phytopathological Society, St. Paul, MN, U.S.A.). The PI for each bacterial mutant was calculated according to the equation $\mathrm{PI}=\Sigma$ (lesion size of leaves from the bacterial mutant/lesion size of leaves from the wild-type bacterium)/number of leaves used for measurement.

In the systemic invasion assay, the pathogenicity of $E$. chrysanthemi 3937 was evaluated as described by Nachin and associates (2001) with minor modification. A volume of $0.05 \mathrm{ml}$ of bacterial suspension with an optical density at $600 \mathrm{~nm}$ of 0.3 was inoculated into the front edge of the African violet cv. Katja leaf. Inoculated plants were kept in a growth chamber with regular water misting ( $5 \mathrm{~min}$ in every $4 \mathrm{~h}$ ) to provide humid conditions.

\section{ACKNOWLEDGMENTS}

We gratefully acknowledge M. L. P. Collins for a critical review of this manuscript. We thank Patricia Steen and Peter W. Hickmott for valuable assistance with microscopic analyses. This project was supported by USDANRICGP award no. 2001-35319-10015 and NSF award no. MCB-0211750.

\section{LITERATURE CITED}

Aguilar, I., Poza-Carrión, C., Guío, A., and Rodríguez-Palenzuela, P. 2002. Erwinia chrysanthemi genes specifically induced during infection in chicory leaves. Mol. Plant Pathol. 3:271-275.

Bauer, D. W., Bogdanove, A. J., Beer, S. V., and Collmer, A. 1994. Erwinia chrysanthemi hrp genes and their involvement in soft-rot pathogenesis and elicitation of the hypersensitive response. Mol. PlantMicrobe Interact. 7:573-581.

Bauer, D.W., Wei, Z. M., Beer, S. V., and Collmer, A. 1995. Erwinia chrysanthemi harpinEch: An elicitor of the hypersensitive response that contributes to soft-rot pathogenesis. Mol. Plant-Microbe Interact. 8:484-491.

Boch, J., Joardar, V., Gao, L., Robertson, T. L., Lim, M., and Kunkel, B. N. 2002. Identification of Pseudomonas syringae pv. tomato genes induced during infection of Arabidopsis thaliana. Mol. Microbiol. 44:73-88.

Bogdanove, A. J., Bauer, D. W., and Beer, S. V. 1998. Erwinia amylovora secretes dspE, a pathogenicity factor and functional avrE homolog, through the hrp (type III secretion) pathway. J. Bacteriol. 180:2244-2247.

Buell, C. R., Joardar, V., Lindeberg, M., Selengut, J., Paulsen, I. T., Gwinn, M. L., Dodson, R. J., Deboy, R. T., Durkin, A. S., Kolonay, J. F., Madupu, R., Daugherty, S., Brinkac, L., Beanan, M. J., Haft, D. H., Nelson, W. C., Davidsen, T., Zafar, N., Zhou, L., Liu, J., Yuan, Q., Khouri, H., Fedorova, N., Tran, B., Russell, D., Berry, K., Utterback, T., Van Aken, S. E., Feldblyum, T. V., D’Ascenzo, M., Deng, W. L., Ramos, A. R., Alfano, J. R, Cartinhour, S., Chatterjee, A. K., Delaney, T. P., Lazarowitz, S. G., Martin, G. B., Schneider, D. J., Tang, X., Bender, C. L., White, O., Fraser, C. M., and Collmer, A. 2003. The complete genome sequence of the Arabidopsis and tomato pathogen Pseudomonas syringae pv. tomato DC3000. Proc. Natl. Acad. Sci. U.S.A. 100:10181-10186.

Chatterjee, A. K., Dumenyo, C. K., Liu, Y., and Chatterjee, A. 2000. Erwinia: Genetics of pathogenicity factors. Pages 236-259 in: Encyclopedia of Microbiology, Vol. 2, 2nd ed. J. Lederberg, ed. Academic Press, New York.

Chiang, S. L., and Mekalanos, J. J. 1998. Use of signature-tagged transposon mutagenesis to identify Vibrio cholerae genes critical for colonization. Mol. Microbiol. 27:797-805.

Collmer, A., and Keen, N. T. 1986. The role of pectic enzymes in plant pathogenesis. Annu. Rev. Phytopathol. 24:383-409.

Coulter, S. N., Schwan, W. R., Ng, E. Y., Langhorne, M. H., Ritchie, H. D., Westbrock-Wadman, S., Hufnagle, W. O., Folger, K. R., Bayer, A. S., and Stover, C. K. 1998. Staphylococcus aureus genetic loci impacting growth and survival in multiple infection environments. Mol. Microbiol. 30:393-404.

DeLisa, M. P., Wu, C. F., Wang, L., Valdes, J. J., and Bentley, W. E. 2001. DNA microarray-based identification of genes controlled by autoinducer 2-stimulated quorum sensing in Escherichia coli. J. Bacteriol. 183:5239-5247.

Expert, D. 1999. Withholding and exchanging iron: Interactions between Erwinia spp. and their plant hosts. Annu. Rev. Phytopathol. 37:307334.

Fouts, D. E., Abramovitch, R. B., Alfano, J. R., Baldo, A. M., Buell, C. R., Cartinhour, S., Chatterjee, A. K., D'Ascenzo, M., Gwinn, M. L., Lazarowitz, S. G., Lin, N. C., Martin, G. B., Rehm, A. H., Schneider, D. J., van Dijk, K., Tang, X. Y., and Collmer, A. 2002. Genomewide identification of Pseudomonas syringae pv. tomato DC3000 promoters controlled by the HrpL alternative sigma factor. Proc. Natl. Acad. Sci. U.S.A. 99:2275-2280.

Franza, T., and Expert, D. 1991. The virulence-associated chrysobactin iron uptake system of Erwinia chrysanthemi 3937 involves an operon encoding transport and biosynthetic functions. J. Bacteriol. 173:6874-6881.

Franza, T., Sauvage, C., and Expert, D. 1999. Iron regulation and pathogenicity in Erwinia chrysanthemi 3937: Role of the Fur repressor protein. Mol. Plant-Microbe Interact. 12:119-128.

Gaudriault, S., Malandrin, L., Paulin, J. P., and Barny, M. A. 1997. DspA, an essential pathogenicity factor of Erwinia amylovora showing homology with AvrE of Pseudomonas syringae, is secreted via the Hrp secretion pathway in a DspB-dependent way. Mol. Microbiol. 26:1057-1069.

Glasner, J. D., Liss, P., Plunkett, G., 3rd, Darling, A., Prasad, T., Rusch, M., Byrnes, A., Gilson, M., Biehl, B., Blattner, F. R., and Perna, N. T. 2003. ASAP, a systematic annotation package for community analysis of genomes. Nucleic Acids Res. 31:147-151.

Goodman, R. N., Kirly, Z., and Wood, K. R. 1986. The Biochemistry and Physiology of Plant Disease. University of Missouri Press, Columbia

Gosink, K. K., Kobayashi, R., Kawagishi, I., and Hase, C. C. 2002. Analy- 
ses of the roles of the three cheA homologs in chemotaxis of Vibrio cholerae. J. Bacteriol. 184:1767-1771.

Hassouni, M. E., Chambost, J. P., Expert, D., Van Gijsegem, F., and Barras, F. 1999. The minimal gene set member $m s r A$, encoding peptide methionine sulfoxide reductase, is a virulence determinant of the plant pathogen Erwinia chrysanthemi. Proc. Natl. Acad. Sci. U.S.A. 96:887-892.

Heithoff, D. M., Conner, C. P., Hanna, P. C., Julio, S. M., Hentschel, U., and Mahan, M. J. 1997. Bacterial infection as assessed by in vivo gene expression. Proc. Natl. Acad. Sci. U.S.A. 94:934-939.

Hugouvieux-Cotte-Pattat, N. 2004. The RhaS activator controls the Erwinia chrysanthemi 3937 genes rhiN, rhiT and rhiE involved in rhamnogalacturonan catabolism. Mol. Microbiol. 51:1961-1974.

Hugouvieux-Cotte-Pattat, N., and Reverchon, S. 2001. Two transporters, TogT and TogMNAB, are responsible for oligogalacturonide uptake in Erwinia chrysanthemi Mol. Microbiol. 41:1125-1132.

Hugouvieux-Cotte-Pattat, N., Condemine, G., Nasser, W., and Reverchon, S. 1996. Regulation of pectinolysis in Erwinia. Annu. Rev. Microbiol. 50:213-257.

Hugouvieux-Cotte-Pattat, N., Blot, N., and Reverchon, S. 2001. Identification of TogMNAB, an ABC transporter which mediates the uptake of pectic oligomers in Erwinia chrysanthemi 3937. Mol. Microbiol. 41:1113-1123.

Ilves, H., Hõrak, R., and Kivisaar, M. 2001. Involvement of $\delta^{\mathrm{s}}$ in starvation-induced transposition of Pseudomonas putida transposon Tn4652. J. Bacteriol. 183:5445-5448.

Kilic, A. O., Herzberg, M. C., Meyer, M. W., Zhao, Z., and Tao, L. 1999. Streptococcal reporter gene-fusion vector for identification of in vivo expressed genes. Plasmid. 42:67-72.

Kim, K. S., Rao, N. N., Fraley, C. D., and Kornberg, A. 2002. Inorganic polyphosphate is essential for long-term survival and virulence factors in Shigella and Salmonella spp. Proc. Natl. Acad. Sci. U.S.A. 99:76757680

Kornberg, A., Rao, N. N., and Ault-Riche, D. 1999. Inorganic polyphosphate: A molecule of many functions. Annu. Rev. Biochem. 68:89-125.

Laatu, M., and Condemine, G. 2003. Rhamnogalacturonate lyase RhiE is secreted by the Out system in Erwinia chrysanthemi. J. Bacteriol. 185:1642-1649.

Lai, Y. C., Peng, H. L., and Chang, H. Y. 2001. Identification of genes induced in vivo during Klebsiella pneumoniae CG41 infection. Infect. Immun. 69:7140-7145

Larsen, M. H., and Boesen, H. T. 2001. Role of flagellum and chemotactic motility of Vibrio anguillarum for phagocytosis by and intracellular survival in fish macrophages. FEMS (Fed. Eur. Microbiol. Soc.) Microbiol Lett. 203:149-152.

Lehoux, D. E., Sanschagrin, F., and Levesque, R. C. 2002. Identification of in vivo essential genes from Pseudomonas aeruginosa by PCR-based signature-tagged mutagenesis. FEMS (Fed. Eur. Microbiol. Soc.) Microbiol. Lett. 210:73-80.

López-Solanilla, E., Llama-Palacios, A., Collmer, A., García-Olmedo, F., and Rodríguez-Palenzuela, P. 2001. Relative effects on virulence of mutations in the sap, pel, and hrp loci of Erwinia chrysanthemi. Mol. Plant-Microbe Interact. 14:386-393.

Mahan, M. J., Slauch, J. M., and Mekalanos, J. J. 1993. Selection of bacterial virulence genes that are specifically induced in host tissues. Science 259:686-688

Mahan, M. J., Tobias, J. W., Slauch, J. M., Hanna, P. C., Collier, R. J., and Mekalanos, J. J. 1995. Antibiotic-based selection for bacterial genes that are specifically induced during infection of a host. Proc. Natl. Acad. Sci. U.S.A. 92:669-673.

Marco, M. L., Legac, J., and Lindow, S. E. 2003. Conditional survival as a selection strategy to identify plant-inducible genes of Pseudomonas syringae. Appl. Environ. Microbiol. 69:5793-5801.

Merrell, D. S., Hava, D. L., and Camilli, A. 2002. Identification of novel factors involved in colonization and acid tolerance of Vibrio cholerae. Mol. Microbiol. 43:1471-1491.

Miller, W. G., and Lindow, S. E. 1997. An improved GFP cloning cassette designed for prokaryotic transcriptional fusions. Gene 191:149-153.

Nachin, L., and Barras, F. 2000. External pH: An environmental signal that helps to rationalize pel gene duplication in Erwinia chrysanthemi. Mol. Plant-Microbe Interact. 13:882-886.

Nachin L., El Hassouni M., Loiseau L., Expert D., and Barras F. 2001. SoxR-dependent response to oxidative stress and virulence of Erwinia chrysanthemi: The key role of SufC, an orphan ABC ATPase. Mol. Microbiol. 39:960-972.

Nasser, W., and Reverchon, S. 2002. H-NS-dependent activation of pectate lyases synthesis in the phytopathogenic bacterium Erwinia chrysanthemi is mediated by the PecT repressor. Mol. Microbiol. 43:733-748.
Nasser, W., Reverchon, S., Condemine, G., and Robert-Baudouy, J. 1994. Specific interactions of Erwinia chrysanthemi KdgR repressor with different operators of genes involved in pectinolysis. J. Mol. Biol. 236:427-440.

Nasser, W., Bouillant, M. L., Salmond, G., and Reverchon, S. 1998. Characterization of the Erwinia chrysanthemi expI-expR locus directing the synthesis of two $\mathrm{N}$-acyl-homoserine lactone signal molecules. Mol. Microbiol. 29:1391-1405.

Okinaka,Y., Yang, C.-H., Perna, N. T., and Keen, N. T. 2002. Microarray profiling of Erwinia chrysanthemi 3937 genes that are regulated during plant infection. Mol. Plant-Microbe Interact. 15:619-629.

O'Toole, R., Milton, D. L., and Wolf-Watz, H. 1996. Chemotactic motility is required for invasion of the host by the fish pathogen Vibrio anguillarum. Mol. Microbiol. 19:625-637.

Perombelon, M. C. M., and Kelman, A. 1980. Ecology of the soft rot erwinias. Annu. Rev. Phytopathol. 18:361-387.

Polissi, A., Pontiggia, A., Feger, G., Altieri, M., Mottl, H., Ferrari, L., and Simon, D. 1998. Large scale identification of virulence genes from Streptococcus pneumoniae. Infect. Immun. 66:5620-5629.

Rainey, P. B. 1999. Adaptation of Pseudomonas fluorescens to the plant rhizosphere. Environ. Microbiol. 1:243-257.

Rashid, M. H., and Kornberg, A. 2000. Inorganic polyphosphate is needed for swimming, swarming, and twitching motilities of Pseudomonas aeruginosa. Proc. Natl. Acad. Sci. U.S.A. 97:4885-4890.

Rashid, M. H., Rao, N. N., and Kornberg, A. 2000a. Inorganic polyphosphate is required for motility of bacterial pathogens. J. Bacteriol. 182:225-227

Rashid, M. H., Rumbaugh, K., Passador, L., Davies, D. G., Hamood, A. N., Iglewski, B. H., and Kornberg, A. 2000b. Polyphosphate kinase is essential for biofilm development, quorum sensing, and virulence of Pseudomonas aeruginosa. Proc. Natl. Acad. Sci. U.S.A. 97:9636-9641.

Reid, J. L., and Collmer, A. 1987. An nptI-SacB-SacR cartridge for constructing directed, unmarked mutation in gram-negative bacteria by marker exchange-eviction mutagenesis. Gene 57:239-246.

Reverchon, S., Rouanet, C., Expert, D., and Nasser, W. 2002. Characterization of indigoidine biosynthetic genes in Erwinia chrysanthemi and role of this blue pigment in pathogenicity. J Bacteriol. 184:654-665.

Reverchon, S., Expert, D., Robert-Baudouy, J., and Nasser, W. 1997. The cyclic AMP receptor protein is the main activator of pectinolysis genes in Erwinia chrysanthemi. J. Bacteriol. 179:3500-3508.

Saier, M. H., and Reizer, J. 1994. The bacterial phosphotransferase system: New frontiers 30 years later. Mol. Microbiol. 13:755-764.

Serres M. H., and Riley M. 2001. MultiFun, a multifunctional classification scheme for Escherichia coli K-12 gene products. Microb. Comp. Genomics 5:205-222.

Shiba, T., Tsutsumi, K., Ishige, K., and Noguchi, T. 2000. Inorganic polyphosphate and polyphosphate kinase: Their novel biological functions and applications. Biochemistry (Moscow). 65:315-323.

Tardy, F., Nasser, W., Robert-Baudouy, J., and Hugouvieux-Cotte-Pattat, N. 1997. Comparative analysis of the five major Erwinia chrysanthemi pectate lyases: Enzyme characteristics and potential inhibitors. J. Bacteriol. 179:2503-2511.

Toth, I. K., Bell, K. S., Holeva, M. C., and Birch, P. R. 2003. Pathogen profile, Soft rot erwiniae: From genes to genomes. Mol. Plant Pathol. 4:17-30.

Valdivia, R. H., and Falkow, S. 1996. Bacterial genetics by flow cytometry: Rapid isolation of Salmonella typhimurium acid-inducible promoters by differential fluorescence induction. Mol. Microbiol. 22:367-378.

Valdivia, R. H., and Falkow, S. 1997. Fluorescence-based isolation of bacterial genes expressed within host cells. Science 277:2007-2011.

Von Kruger, W. M. A., Humphreysa, S., and Ketley, J. M. 1999. A role for the PhoBR regulatory system homologue in the Vibrio cholerae phosphate limitation response and intestinal colonization. Microbiology 145:2463-2475.

Wang, J., Mushegian, A., Lory, S., and Jin, S. 1996. Large-scale isolation of candidate virulence genes of Pseudomonas aeruginosa by in vivo selection. Proc. Natl. Acad. Sci. U.S.A. 93:10434-10439.

Wassenaar, T. M., and Gaastra, W. 2001. Bacterial virulence: Can we draw the line? FEMS (Fed. Eur. Microbiol. Soc.) Microbiol. Lett. 201:1-7.

Wei, Y., Lee, J. M., Richmond, C., Blattner, F. R., Rafalski, J. A., and LaRossa, R. A. 2001. High-density microarray-mediated gene expression profiling of Escherichia coli. J. Bacteriol. 183:545-556.

Wu, Y., Lee, S. W., Hillman, J. D., and Progulske-Fox, A. 2002. Identification and testing of Porphyromonas gingivalis virulence genes with a pPGIVET system. Infect. Immun. 70:928-937.

Yang, C.-H., Gavilanes-Ruiz, M., Okinaka, Y., Vedel, R., Berthuy, I., Boccara, M., Chen, J. W., Perna, N. T., and Keen, N. T. 2002. hrp genes of Erwinia chrysanthemi 3937 are important virulence factors. Mol. Plant-Microbe Interact. 15:472-480. 